\title{
Machine learning-based prediction of outcomes of the endoscopic endonasal approach in Cushing disease: is the future coming?
}

\author{
${ }^{*}$ Matteo Zoli, MD, PhD,,,2 Victor E. Staartjes, BMed, ${ }^{3,4}$ Federica Guaraldi, MD, PhD,,2 \\ Filippo Friso, MD, ${ }^{1}$ Arianna Rustici, MD, ${ }^{5,6}$ Sofia Asioli, MD, ${ }^{1,2,7}$ Giacomo Sollini, MD1,8 \\ Ernesto Pasquini, MD, ${ }^{1,8}$ Luca Regli, MD, ${ }^{3}$ Carlo Serra, MD, ${ }^{3}$ and Diego Mazzatenta, MD ${ }^{1,2}$ \\ ${ }^{1}$ Pituitary Unit, Center for the Diagnosis and Treatment of Hypothalamic-Pituitary Diseases, IRCCS Institute of Neurological \\ Sciences of Bologna; ${ }^{2 D}$ epartment of Biomedical and Motor Sciences (DIBINEM), University of Bologna, Italy; ${ }^{3}$ Department of \\ Neurosurgery, Clinical Neuroscience Center, University Hospital of Zurich, University of Zurich, Switzerland; ${ }^{4}$ Neurosurgery, \\ Amsterdam Movement Sciences, Amsterdam UMC, Vrije Universiteit Amsterdam, The Netherlands; ${ }^{5}$ Department of \\ Neuroradiology, IRCCS Istitute of Neurological Sciences of Bologna; ${ }^{6}$ Department of Experimental, Diagnostic and Specialty \\ Medicine (DIMES), University of Bologna; ${ }^{7}$ Section of Anatomic Pathology 'M. Malpighi' at Bellaria Hospital, Bologna; and ${ }^{8}$ ENT \\ Department, Bellaria Hospital, Bologna, Italy
}

OBJECTIVE Machine learning (ML) is an innovative method to analyze large and complex data sets. The aim of this study was to evaluate the use of ML to identify predictors of early postsurgical and long-term outcomes in patients treated for Cushing disease (CD).

METHODS All consecutive patients in our center who underwent surgery for CD through the endoscopic endonasal approach were retrospectively reviewed. Study endpoints were gross-tumor removal (GTR), postsurgical remission, and long-term control of disease. Several demographic, radiological, and histological factors were assessed as potential predictors. For ML-based modeling, data were randomly divided into 2 sets with an $80 \%$ to $20 \%$ ratio for bootstrapped training and testing, respectively. Several algorithms were tested and tuned for the area under the curve (AUC).

RESULTS The study included 151 patients. GTR was achieved in 137 patients (91\%), and postsurgical hypersecretion remission was achieved in 133 patients (88\%). At last follow-up, 116 patients $(77 \%)$ were still in remission after surgery and in 21 patients $(14 \%)$, CD was controlled with complementary treatment (overall, of 131 cases, $87 \%$ were under control at follow-up). At internal validation, the endpoints were predicted with AUCs of $0.81-1.00$, accuracy of $81 \%-100 \%$, and Brier scores of $0.035-0.151$. Tumor size and invasiveness and histological confirmation of adrenocorticotropic hormone (ACTH)-secreting cells were the main predictors for the 3 endpoints of interest.

CONCLUSIONS ML algorithms were used to train and internally validate robust models for all the endpoints, giving accurate outcome predictions in CD cases. This analytical method seems promising for potentially improving future patient care and counseling; however, careful clinical interpretation of the results remains necessary before any clinical adoption of ML. Moreover, further studies and increased sample sizes are definitely required before the widespread adoption of $M L$ to the study of $C D$.

https://thejns.org/doi/abs/10.3171/2020.3.FOCUS2060

KEYWORDS machine learning; outcome; predictors; Cushing disease; ACTH-secreting tumor; endoscopic endonasal surgery

ABBREVIATIONS $\mathrm{ACTH}=$ adrenocorticotropic hormone; $\mathrm{AUC}=$ area under the curve; $\mathrm{CD}=$ Cushing disease $\mathrm{CS}=$ cavernous sinus; $\mathrm{DI}=$ diabetes insipidus; $\mathrm{EEA}=$ endoscopic endonasal approach; GBM = gradient boosting machine; GLM = generalized linear model; GTR = gross-tumor removal; IPSS = inferior petrosal sinus sampling; $\mathrm{KNN}$ = k-nearest neighbor; $\mathrm{ML}$ = machine learning; NPV = negative predictive value; $\mathrm{PAS}=$ periodic acid Schiff; $\mathrm{PPV}=$ positive predictive value; $\mathrm{RF}=$ random forest; $\mathrm{ROC}$ $=$ receiver operating characteristic; SF-1 = steroidogenic factor $-1 ;$ SVM = support vector machine.

ACCOMPANYING EDITORIAL DOI: 10.3171/2020.3.FOCUS20213.

SUBMITTED January 31, 2020. ACCEPTED March 4, 2020.

INCLUDE WHEN CITING DOI: 10.3171/2020.3.FOCUS2060.

${ }^{*}$ M.Z. and V.E.S. contributed equally to this work and share first authorship. 
I $\mathrm{N}$ recent years, machine learning (ML) has been increasingly reported in the medical literature. ${ }^{22,40,44} \mathrm{ML}$ is a branch of artificial intelligence science that allows the analysis of large amounts of variables and parameters: so-called "big data." $5,12,32$ Progressive advancements in diagnostics and therapeutics have led to extraordinary increases in the number and complexity of collected data in medicine, in order to obtain the most comprehensive and multiaxial assessment of disease possible and to tailor its management on the basis of the specific features of each patient. ${ }^{5,12,32}$ The empowerment of modern computational machines has allowed the construction of complex models of artificial intelligence able to process enormous and heterogeneous data sets and to predict a disease or treatment outcome without being explicitly programmed. Indeed, after the creation of robust models using training data, ML can enable computers to perform automatic identification of predictive factors and learn complex risk factor interactions for the outcome(s) of interest in new patient cohorts. ${ }^{12,28,35,47-49}$

Recent applications of ML to neurosurgery include segmentation of brain tumors and other critical targets (such as basal ganglia for deep brain stimulation), prediction of the location of an epileptic focus based on videoelectroencephalographic monitoring, stratification of clinical outcome after subarachnoid hemorrhage, and prediction of the results of surgery for intraxial brain tumor, discectomy, or laminectomy. 1,3,13-15,17,18,21,29-31,33,36,55-60,63,64 However, difficulties in the interpretation of ML results and the need for specifically trained research support staffs have prevented the wide adoption of ML in neurosurgery. ${ }^{9,51,52}$

Pituitary surgery may represent an ideal field for the application of ML. ${ }^{24,37,57,60,61}$ Indeed, the management of pituitary tumors is very complex and requires a dedicated team made up of neurosurgeons, neuroendocrinologists, ENTs, neuroradiologists, and radiotherapists, flanked by ophthalmologists, oncologists, and neurologists. ${ }^{2}$ Therefore, heterogeneous and sometimes controversial data, coming from biochemical assays, ophthalmological tests, neurological clinical and instrumental evaluations, and MRI and CT scan examinations, performed at diagnosis and follow-ups, have to be integrated and critically analyzed to assess patient outcomes. ${ }^{25,48,60,61,67}$

Among the different pituitary afflictions, Cushing disease (CD) is one of the more challenging, with variable rates of remission and high risk of recurrence. ${ }^{6,27,48,57,66}$ Therefore, the outcomes of these patients are often the most difficult to predict preoperatively. The aim of this study was to evaluate the adoption of ML analysis for the identification of predictive models for the extent of tumor resection and postsurgical and long-term outcomes in a large and consistent cohort of patients with CD treated with an endoscopic endonasal approach (EEA).

\section{Methods}

The study included all consecutive patients with CD who underwent surgery via EEA during the period from May 1998 to December 2017 and had at least 12 months of follow-up at the Pituitary Unit, Center for the Diagnosis and Treatment of Hypothalamic-Pituitary Diseases,
IRCCS Institute of Neurological Sciences of Bologna, Italy.

CD diagnosis was based on clinical, biochemical, and radiological criteria, according to international guidelines. ${ }^{23,43,48}$ Patients who were treatment naïve and those who had already undergone treatment were included. Patients with Nelson's syndrome or silent adrenocorticotropic hormone (ACTH)-secreting adenomas were excluded. All surgeries were performed by a multidisciplinary team that included an expert pituitary neurosurgeon and a dedicated ENT surgeon, who followed a previously reported technique. ${ }^{19,20}$

Preoperatively, patients underwent biochemical, endocrinological, neurological, and visual-field examinations and a 1.5-T MRI with gadolinium contrast medium. In cases with highly suspicious features or previous histological evidence of ACTH-secreting pituitary adenoma/ cell hyperplasia but negative MRI findings, patients underwent 3-T MRI with gadolinium contrast medium and, if that was also negative, inferior petrosal sinus sampling (IPSS). ${ }^{43}$

Based on MRI findings, lesions were divided into micro- $($ size $<1 \mathrm{~cm})$, macro- $(>1 \mathrm{~cm})$, or MRI-undetectable adenoma and then classified according to Hardy-Wilson score. If cavernous sinus (CS) invasion was suspected at preoperative MRI, it was classified according to Knosp grade and confirmed by direct surgical inspection. ${ }^{34,39,67}$

Clinical, biochemical, radiological, and pathological data were retrospectively collected from patient records from the first hospital access to the last follow-up evaluation.

All slides were reviewed by an expert pituitary pathologist (S.A.). Histochemical stains included periodic acid Schiff (PAS) and Gordon-Sweet silver stain for reticulin, and immunohistochemical analysis was performed for pituitary hormones, pituitary transcription factor-1 (Pit-1), steroidogenic factor-1 (SF-1), estrogen receptor $\alpha(\mathrm{ER} \alpha)$, and cytokeratin CAM 5.2. Tumor invasion and proliferation were defined as $>2 / 10$ mitoses per high-power field (HPF; $0.30 \mathrm{~mm}^{2}, \times 400$ magnification), Ki-67 $\geq 3 \%$, and p53 expression $>10$ strongly positive nuclei/10 HPF in cells located within the areas with the highest nuclear labeling (hotspots). ${ }^{45}$

Intra- and postoperative complications were reported to determine the surgical morbidity rate. Tumor resection was assessed as radical (no visible remnants) or nonradical (in case of visible tumor remnants) according to MRI performed 3 months after surgery (the first surgery in case of repeated procedures). Further MRI was performed every 6-12 months. Cortisol levels were checked at postoperative days 1 and 2 at 8 AM (a significant drop was considered for cortisol levels $<5 \mu \mathrm{g} / \mathrm{dl}) .{ }^{42}$ Cortisol levels were rechecked at the 1-, 3-, 6-, and 12-month follow-ups, and then annually, in cases with manifestations suggestive for hypocortisolism; levels $<2 \mu \mathrm{g} / \mathrm{dl}$ defined CD remission. A low-dose ACTH test was performed in cases for which the cortisol levels were not clearly diagnostic. ${ }^{42}$ Postsurgical remission was defined for demonstrated hypersecretion normalization at 1 to 3-6 months after surgery (the first surgery in case of repeated procedures). In case of clinical manifestations or biochemical or MRI findings of 
TABLE 1. Potential predictors and outcomes incorporated in $M L$ analysis

\begin{tabular}{lcccc}
\hline & $\begin{array}{c}\text { Patient \& Neuroradiological } \\
\text { Characteristics }\end{array}$ & Preop & Intraop & Postop \\
\hline $\begin{array}{l}\text { Potential } \\
\text { predictors }\end{array}$ & $\begin{array}{c}\text { Patient age \& sex; diagnosis } \\
\text { confirmed by IPSS; tumor size; } \\
\text { Hardy, Wilson, \& Knosp grades }\end{array}$ & $\begin{array}{c}\text { Hypopituitarism, Dl; previous } \\
\text { operations; medical, radia- } \\
\text { tion treatment }\end{array}$ & $\begin{array}{c}\text { Bony tumor or cavern- } \\
\text { ous invasiveness; } \\
\text { CS invasion }\end{array}$ & Hypopituitarism, DI \\
\hline Outcomes & - & - & GTR & $\begin{array}{c}\text { Remission early postop or long-term } \\
\text { (after op \& other potential treatments) }\end{array}$ \\
\hline
\end{tabular}

alterations suggestive for disease recurrence, patients underwent appropriate screening for hypercortisolism (i.e., midnight salivary cortisol and/or dexamethasone [DEX] $1 \mathrm{mg}){ }^{38,42}$ Other pituitary axes were tested according to timing and methods suggested by guidelines; replacement treatment was started in case of hormone insufficiency. ${ }^{42}$

Patients also underwent surgical, ophthalmological, and neurological evaluations at 1, 3, 6, and 12 months of follow-up, and then annually. In addition, evaluations were also performed for manifestations suspicious for mass effects secondary to tumor remnant growth. ${ }^{38,42}$ Complementary treatments, such as postoperative medical and/ or radiation therapies and bilateral surrenalectomy, were considered. Long-term biochemical outcome was defined based on disease control or persistence at last follow-up (cases for which bilateral adrenalectomy was performed were considered as not controlled).

The study was approved by an interhospital Ethical Committee of Bologna City (protocol CE17143, February 2018). Patients gave written informed consent authorizing the use of their clinical data anonymously.

\section{Analysis}

Potential predictors and outcomes are listed in Table 1. Continuous data are presented as mean \pm SD and categorical data as numbers and percentages.

For ML-based modeling, data were randomly split into 2 sets in a 80\%/20\% ratio for training and testing, respectively. In the training set, the models were trained and continually validated using bootstrapping. Random forests (RFs), support vector machine (SVM), gradient boosting machine (GBM), Bayesian generalized linear models (GLMs), k-nearest neighbor (KNN), and decision trees based on the C5.0 algorithm, as well as artificial neural networks with a single hidden layer, were tested. After hyperparameter tuning, the model with the best performance during bootstrapping was selected based on the area under the curve (AUC) of the receiver operating characteristic (ROC), then evaluated on the test set for internal validation. Whenever relevant class imbalance was present, we applied synthetic minority oversampling (SMOTE) to the training set to ensure model robustness. ${ }^{59}$ At internal validation, calibration (i.e., the degree to which predicted probabilities correspond to true, observed probabilities) was assessed using the Brier score (range 0-1, with values closer to 0 indicating greater calibration). AUC-based individual variable importance was obtained for each model. Final models were based on SVMs, RFs, and neural networks.
All analyses were carried out in $\mathrm{R}$ version 3.5.2 (The $\mathrm{R}$ Foundation for Statistical Computing). The statistical code is provided as Supplementary Content 1.

\section{Results \\ Study Sample, Surgical Approach, and Histological Findings}

In total, 151 patients (107 female, $70.8 \%$ ) were included, for a total of 170 surgical procedures. The mean age at surgery was $41.1 \pm 16.6$ years, and 134 patients $(88.7 \%)$ were treatment naïve, 17 (11.3\%) had already undergone surgery, and 18 (11.9\%) had already undergone medical therapy. Thirty patients (19.8\%) presented with hypopituitarism, 9 (6\%) with visual disturbances, and $6(4 \%)$ with ophtalmoplegia (Table 2).

Adenomas were detected with preoperative MRI in 115 patients (76.2\%); 80 were microadenomas (2 were ectopic, 1 located in the CS and the other in the pituitary stalk) and 35 were macroadenomas (Table 2). Intraoperative inspection demonstrated CS invasion in 7 cases (4.6\%). A standard midline transsphenoidal approach was performed in 167 cases (98.2\%), an ethmoido-pterygo-sphenoidal approach was performed in 2 cases of macroadenomas extending to the CS anteroinferior and lateral compartments, while the pituitary stalk microadenoma was removed through a supradiaphragmatic approach (Table 2).

An ACTH-secreting adenoma or diffuse corticotroph hyperplasia was detected in $82.4 \%$ of the cases at histological examination; in the other cases, the specimen was insufficient for diagnosis.

The morbidity rate was $3.4 \%$ and included epistaxis (n $=1)$, CSF leakage $(n=1)$, pneumonia $(n=3)$, myocardial infarction $(n=1)$, and pulmonary embolisms $(n=2)$. No surgical mortality was observed in the series.

\section{Early Postsurgical and Long-Term Outcomes}

Gross-tumor removal (GTR) was achieved in 137 cases $(90.8 \%)$, while the postsurgical remission rate was $88.1 \%$ (133 patients; 95\% in micro-, $82.6 \%$ in macro-, and $77.8 \%$ in MRI-undetectable adenomas). Disease persisted in 18 patients (11.9\%; 6 macro-, 4 micro-, and 8 MRI-undetectable adenomas), with additional treatment of second surgery in 11 patients, radiation therapy in 8 patients, medical therapy in 5 patients, and bilateral adrenalectomy in 7 patients. Twenty-five patients (18.2\%; 6 macro-, 11 micro-, and 8 MRI-undetectable adenomas) had disease recurrence after a mean of 5 years (range 1-16 years) and were treated with a second surgery $(n=12)$, radiation therapy $(n$ 
TABLE 2. Main demographic, clinical, and radiological features and previous treatments at the time of first surgery performed at our center

\begin{tabular}{lccc}
\hline & Total $(\mathrm{n}=151)$ & Males $(\mathrm{n}=44)$ & Females $(\mathrm{n}=107)$ \\
\hline Age at diagnosis, yrs & $39.7 \pm 2.7(14-79)$ & $35.2 \pm 5.5(14-79)$ & $41.8 \pm 3.1(14-75)$ \\
\hline Age in yrs at 1st op at our center & $41.1 \pm 16.6(14-76)$ & $38.1 \pm 18.0(14-76)$ & $42.3 \pm 15.8(14-76)$ \\
\hline MRl features & & & \\
\hline Macroadenoma $(>1 \mathrm{~cm})$ & $35(23.2)$ & $13(29.5)$ & $22(20.6)$ \\
\hline Hardy grade $\geq 3$ & $5(0.33)$ & $5(11.4)$ & $0(0)$ \\
\hline Wilson grade $\mathrm{E}$ & $12(7.9)$ & $4(9.0)$ & $20(18.7)$ \\
\hline Knosp grade $\geq 3$ & $6(0.4)$ & $4(9.0)$ & $60(56.1)$ \\
\hline Microadenoma $(<1 \mathrm{~cm})$ & $80(53.0)$ & $20(45.5)$ & $60(56.1)$ \\
\hline Intrasellar & $78(51.7)$ & $18(41.0)$ & $0(0)$ \\
\hline Ectopic & $2(1.3)$ & $2(4.5)$ & $12(11.2)$ \\
\hline Undetectable adenoma & $36(23.8)$ & $11(25)$ & $12(11.2)$ \\
\hline Previous medical therapy & $18(11.9)$ & $6(13.6)$ & $18(16.8)$ \\
\hline Previous op & $17(11.3)$ & $5(11.4)$ & $4(0.4)$ \\
\hline Hypopituitarism & $30(19.9)$ & $12(27.3)$ & $0(0)$ \\
\hline Bitemporal hemianopia & $6(4)$ & $2(4.5)$ & $3(2.8)$ \\
\hline Bitemporal quadrantopia & $1(0.7)$ & $1(2.3)$ & \\
\hline Ophtalmoplegia & $6(4)$ & $3(6.8)$ & \\
\hline Vas & & & \\
\hline
\end{tabular}

Values are presented as mean $\pm \mathrm{SD}$ (range) or number of patients (\%).

$=10)$, medical therapy $(\mathrm{n}=4)$, or bilateral adrenalectomy $(n=6)$ (Tables 3 and 4).

Eighteen patients (11.9\%) developed hypopituitarism and $27(18 \%)$ central diabetes insipidus (DI; permanent in 6 and transient in 21). All 7 patients with preoperative bitemporal hemi-/quadrantopia improved after surgery. Out of 6 patients with preoperative ophtalmoplegia, 4 (66.7\%) recovered and 2 (33.3\%) improved; no ophthalmological or neurological complications occurred (Tables 3 and 4).

At last follow-up (mean $92.3 \pm 12.0$ months), 116 patients $(76.8 \%$; $71.4 \%$ macro-, $83.8 \%$ micro-, and $66.7 \%$ MRI-undetectable adenomas) were in biochemical remission after single/repeated surgery and in 21 patients (13.9\%) CD was controlled by complementary treatment, with CD considered under control at follow-up in $137 \mathrm{pa}-$ tients overall (Tables 3 and 4).

Cortisol levels dropped to under $5 \mu \mathrm{g} / \mathrm{dl}$ in 64 (71.9\%) out of 89 patients (71.9\%; 8 macro-, 42 micro-, and 14 MRI-undetectable adenomas), for whom an 8 AM sample on postsurgery day 1 or 2 was available. Sixty-one patients $(95.3 \%)$ had long-term remission (56 after a single surgery and 5 after 2 surgeries), while 3 patients (5\%) had

TABLE 3. Surgical outcome

\begin{tabular}{lcccr}
\hline $\begin{array}{c}\text { Disease } \\
\text { Outcome }\end{array}$ & $\begin{array}{c}\text { Total } \\
(\mathrm{n}=151)\end{array}$ & $\begin{array}{c}\text { Macroadenoma } \\
(\mathrm{n}=35)\end{array}$ & $\begin{array}{c}\text { Microadenoma } \\
(\mathrm{n}=80)\end{array}$ & $\begin{array}{c}\text { Negative } \\
(\mathrm{n}=36)\end{array}$ \\
\hline Remission & $133(88.1)$ & $29(82.6)$ & $76(95)$ & $28(77.8)$ \\
\hline Persistence & $18(11.9)$ & $6(17.4)$ & $4(5)$ & $8(22.2)$ \\
\hline
\end{tabular}

Values are presented as number of patients (\%). disease persistence. Eighteen (72\%) of 25 patients without an early drop in cortisol levels had long-term disease remission, $12(48 \%)$ after a single surgery, and $6(24 \%)$ after 2 surgeries.

\section{Analysis}

A powerful and robust ML model was obtained for every outcome after extensive hyperparameter optimization (Tables 5 and 6).

The model predicting GTR was characterized by an AUC of $0.988 ; 96.8 \%$ accuracy, $96.4 \%$ specificity, and $100 \%$ sensitivity; $100 \%$ positive predictive value (PPV) and $75 \%$ negative predictive value (NPV); an F1 score of 0.982 ; and a Brier score of 0.035 . Variables strongly associated with outcome were patient age, tumor visualization at preoperative MRI, tumor size $<10 \mathrm{~mm}$, low Hardy-Wilson grade, histological confirmation of hyperplasia/adenoma, and postoperative hypopituitarism. As expected, Knosp grade, CS invasion, and persistent ACTH hypersecretion were negative prognostic factors (Tables 5 and 6).

The model predicting short-term postsurgical remission had an AUC of 1.00, with accuracy of specificity, sensitivity, PPV, and NPV of $100 \%, \mathrm{~F} 1$ score of 1.00 , and Brier score of 0.097 . The more relevant parameters associated with outcome were age and female sex, tumor visualization at preoperative MRI, size $<10 \mathrm{~mm}$, low Hardy-Wilson grade, histological confirmation of ACTH adenoma, pre-/postoperative hypopituitarism, and presurgical medical treatment. Knosp grade, CS invasion, and persistent ACTH hypersecretion were negative prognostic factors (Tables 5 and 6).

The model predicting long-term disease cure after surgery or combined treatment presented an AUC of 0.783 
TABLE 4. Outcome at last follow-up

\begin{tabular}{lcccc}
\hline & $\begin{array}{c}\text { Microadenoma } \\
(\mathrm{n}=80)\end{array}$ & $\begin{array}{c}\text { Macroadenoma } \\
(\mathrm{n}=35)\end{array}$ & $\begin{array}{c}\text { MRI-Undetectable Adenoma } \\
(\mathrm{n}=36)\end{array}$ & Total \\
\hline Remission after op only & $67(83.8)$ & $25(71.4)$ & $24(66.7)$ & $116(76.8)$ \\
\hline Remission after op \& complementary treatments & $6(7.5)$ & $5(14.3)$ & $10(27.8)$ & $21(13.9)$ \\
\hline Uncontrolled disease & $3(3.8)$ & $1(2.9)$ & $0(0)$ & $4(2.6)$ \\
\hline Death from pituitary carcinoma & $0(0)$ & $1(2.9)$ & $0(0)$ & $1(0.7)$ \\
\hline
\end{tabular}

Values are presented as number of patients (\%).

and an accuracy of $80.7 \%$. Sensitivity and specificity were 95.7\% and $37.5 \%$ and PPV and NPV were $81.5 \%$ and $75.0 \%$, respectively. The F1 score was 0.880 and the Brier score was 0.151 . The more relevant prognostic factors of outcome were age and female sex, tumor visualization at preoperative MRI, size $<10 \mathrm{~mm}$, low Hardy-Wilson grade, histological confirmation of ACTH adenoma, pre-/ postoperative hypopituitarism, and presurgical medical treatment. Knosp grade, CS invasion, and persistent ACTH hypersecretion were negative prognostic factors (Tables 5 and 6).

\section{Discussion}

We have demonstrated in our large homogenous cohort of 151 patients who underwent CD surgery performed through EEA that ML is a reliable analytical method for predicting the extent of tumor removal and the chances of postsurgical remission and long-term control of disease. Indeed, at internal validation, all endpoints analyzed in this study were predicted with AUCs of 0.81-1.00, accuracy of $81 \%-100 \%$, and Brier scores of 0.035-0.151.

$\mathrm{CD}$ is a very challenging condition, characterized by variable rates of remission and high risk of recurrence. ${ }^{9,10}$, 24,42,43,46,50,53 Because of the lack of certain and reliable predictors, it is often difficult to predict each patient's shortand long-term outcomes. ${ }^{4,7,9-11,16,24,41-43,46,50,53,54,62}$ Indeed, in a large series of 230 consecutive CD patients who underwent surgery by EEA, Cebula et al. demonstrated that the presence of a microadenoma and histological confirmation of ACTH secretion were the only predictors of positive outcome. ${ }^{7}$ Conversely, Shin et al., analyzing 50 patients with CD treated through EEA, found no significant differences in the short-term remission rate among patients with micro-, macro-, or MRI-undetectable adenoma, while female sex and younger age were associated with a higher short-term (but not long-term) remission rate. ${ }^{54}$ Finally, CS invasion tended to be associated with a more unfavorable outcome, although this finding did not reach statistical significance in their study. ${ }^{54}$ As suggested by Shin et al., it could not be excluded that these difficulties in identifying certain prognostic factors may have been due to the small sample of CD series and the scant number of patients in each category, which could hamper statistical analysis. ${ }^{54}$

Artificial intelligence methods of data analysis, such as ML, may overcome such limitations, revealing data associations otherwise not demonstrable. ${ }^{51,52,60}$ Indeed, differently from traditional statistics, these methods enable evaluation of the multitude of nonlinear interactions among risk factors and therefore appear promising in the analysis of complex disorders such as CD..$^{22,40,44}$ Supervised learning ML algorithms are based on the machine's ability to "learn" from labeled training data to produce predictive models, which are tested on previously unseen data. ${ }^{51,52,60}$ Differently from traditional programming models, which require a set of instructions provided manually by the operator to generate a desired output from input variables, in the ML algorithm the input and the desired outcome(s) are provided together. ${ }^{51,52,60}$ Then, the computer tries to define what rules combine the provided sets of data. Therefore, the final output of the algorithm is a predictive model whose accuracy is tested on a second set of data, not previously analyzed by the computer. ${ }^{51,52,60}$ Based on these theoretical premises, artificial intelligence may provide powerful and accurate prediction models to improve patient-tailored therapies and thus potentially improve patient care and counseling. ${ }^{52}$

Specifically, ML has been applied to neurosurgery to improve preoperative diagnostic accuracy (i.e., for brain tumor segmentation, radiological segmentation, and detection of seizures at points of video electroencephalography and intraoperative tumor demarcation), and also for prediction (i.e., laterality of epileptogenic foci; patient survival in brain gliomas and after subarachnoid hemorrhage; and outcomes of epilepsy surgery, spine surgery, and deep brain stimulation for Parkinson disease). ${ }^{51,52,60}$ The application of ML to pituitary surgery is very preliminary but appears promising since some studies have demonstrated that ML accurately predicted the extent of tumor resection or postsurgical recurrence in EEA, as well as the risk of complications, particularly of postoperative CSF leak. ${ }^{24,37,57,60,61}$

Our study confirmed the results of Shin et al. on the importance of sex and age for short-term biochemical remission, but it also demonstrated that these parameters, together with others such as tumor detection at MRI, size $<10 \mathrm{~mm}$, Hardy-Wilson grade and histological confirmation of ACTH secretion, pre-/postoperative hypopituitarism, and presurgical medical treatment, also have predictive roles for long-term remission. ${ }^{54}$ Moreover, our study demonstrated that tumor detection at MRI and size $<10 \mathrm{~mm}$, as well as grade 1A Hardy-Wilson score and histological confirmation of ACTH-secreting cells, were associated with a higher chance of GTR. Jagannathan et al. suggested that the lack of postoperative disease control could be due to small tumor islets lying in the pseudocapsule, able to sustain hormone hypersecretion although undetectable at MRI. ${ }^{26}$ According to our results, postsurgical 
TABLE 5. Weight of each variable in the determination of GTR and early postsurgical and long-term disease remission according to 4 ML models applied to statistical analysis

\begin{tabular}{|c|c|c|c|}
\hline Variable & GTR & Biochemical Remission Postop & Hypersecretion Control After Op \& Treatments \\
\hline \multicolumn{4}{|l|}{ Preop } \\
\hline Female sex & 2.4 & 13.9 & 14.3 \\
\hline Age in yrs & 100.0 & 100.0 & 81.5 \\
\hline \multicolumn{4}{|l|}{ Tumor size } \\
\hline Not visible & - & - & - \\
\hline Microadenoma & 5.9 & 81.2 & 20.9 \\
\hline Macroadenoma & 3.3 & 9.1 & 7.8 \\
\hline IPSS & 2.3 & 5.9 & 16.3 \\
\hline \multicolumn{4}{|l|}{ Hardy grade } \\
\hline 0 & - & - & - \\
\hline 1 & 4.4 & 76.9 & 25.8 \\
\hline 2 & 2.5 & 3.9 & 3.5 \\
\hline 3 & 0.6 & 1.7 & 0.6 \\
\hline \multicolumn{4}{|l|}{ Wilson grade } \\
\hline 0 & - & - & - \\
\hline 1 & 6.8 & 68.4 & 15.7 \\
\hline 2 & 2.7 & 9.8 & 4.8 \\
\hline 3 & 1.4 & 0.0 & 0.0 \\
\hline 4 & - & - & - \\
\hline 5 & - & - & - \\
\hline 6 & 1.4 & 4.0 & 0.8 \\
\hline \multicolumn{4}{|l|}{ Knosp grade } \\
\hline 0 & - & - & - \\
\hline 1 & 1.4 & 5.7 & 1.7 \\
\hline 2 & 1.35 & 0.0 & 0.0 \\
\hline 3 & 1.2 & 0.0 & 0.0 \\
\hline 4 & 0.4 & 1.2 & 0.0 \\
\hline \multicolumn{4}{|l|}{ Intraop } \\
\hline \multicolumn{4}{|l|}{ Invasion } \\
\hline None & - & - & - \\
\hline CS & 1.9 & 0.1 & 1.1 \\
\hline Bone & 1.3 & 0.0 & 0.0 \\
\hline CS \& bone & 1.6 & 0.0 & 0.0 \\
\hline \multicolumn{4}{|l|}{ ICSI } \\
\hline None & - & - & - \\
\hline CS compression & 2.2 & 0.8 & 0.0 \\
\hline Focal & - & - & - \\
\hline Diffuse & 4.1 & 16.2 & 0.9 \\
\hline Lat compartment & 0.7 & 0.9 & 0.0 \\
\hline \multicolumn{4}{|l|}{ Pituitary function } \\
\hline None & - & - & - \\
\hline Partial anterior hypopituitarism & 1.4 & 12.7 & 13.2 \\
\hline Complete anterior hypopituitarism & 0.0 & 0.0 & 0.0 \\
\hline Panhypopituitarism w/ DI & - & - & - \\
\hline GH deficit & 1.7 & 13.4 & 3.2 \\
\hline Gonadotroph deficit & 4.5 & 5.1 & 2.8 \\
\hline Thyrotroph deficit & 3.8 & 4.4 & 3.8 \\
\hline $\mathrm{Dl}$ & 2.6 & 0.0 & 0.0 \\
\hline
\end{tabular}


TABLE 5. Weight of each variable in the determination of GTR and early postsurgical and long-term disease remission according to $4 \mathrm{ML}$ models applied to statistical analysis

\begin{tabular}{lccc}
\hline \multicolumn{1}{c}{ Variable } & GTR & Biochemical Remission Postop & Hypersecretion Control After Op \& Treatments \\
\hline Intraop (continued) & & & \\
\hline Prior op & 1.9 & 3.7 & 5.8 \\
\hline Prior medical treatment & 3.9 & 16.8 & 15.6 \\
\hline Postop & & & \\
\hline Histology & - & - & - \\
\hline No tumor & 10.5 & 0.0 & 0.0 \\
\hline Corticotroph hyperplasia & 6.3 & 28.5 & 10.6 \\
\hline ACTH adenoma & 33.2 & 25.2 & 100 \\
\hline Persistent ACTH hypersecretion & 1.8 & 12.1 & 0.2 \\
\hline GH deficit & 5.1 & 11.7 & 8.2 \\
\hline Gonadotroph deficit & 2.0 & 5.9 & 18.7 \\
\hline Thyrotroph deficit & 1.6 & 33.9 & 2.6 \\
\hline Transient DI & 3.6 & 12.3 & 0.2 \\
\hline Persistent DI & & & \\
\hline
\end{tabular}

hypopituitarism also appeared to be associated with a better chance of disease cure/control, but not with GTR. This finding may be explained by the fact that achieving radical resection of the tumor by also removing the pseudocapsule increases the chance of cure but also of pituitary damage, with consequent hypopituitarism. Higher Knosp grade exhibited a relatively low impact on CD remission, while the intraoperative demonstration of invasiveness was more strongly associated with negative short- and long-term outcomes, as suggested by Vallette-Kasic et al..$^{65}$

However, we consider all predictive models given by ML to require clinical interpretation before any use to avoid overemphasizing simple mathematical correlations with no endocrinological or surgical significance. Therefore, this study must be considered a preliminary experience, which should be confirmed by further studies. Its main strengths are the consistency of the study sample, the large number of available patient and tumor information, and the long-term follow-up. On the other hand, the retrospective design and the relatively small sample size, despite being among the largest available in the literature, together with the lack of 8 AM cortisol at postoperative days 1 and 2 in the majority of the patients, represent study limitations. The precision of the model predicting the long-term control of disease has been hampered by the heterogeneity in the postoperative complementary treatments, such as second surgeries, medical and radiation therapies, and the lack of control cases requiring bilateral adrenalectomy; however, all of these cases have been included to test ML outcome prediction in a real clinical scenario.

\section{Conclusions}

The complexity of $\mathrm{CD}$ in terms of clinical, radiological, and histological presentation, as well as associated diagnostic and therapeutic issues, makes this disease an ideal candidate for ML analysis. Based on this preliminary evaluation, ML appears promising in predicting GTR as well as early postsurgical and long-term outcomes, thus improving patient-tailored care and counseling. On the

TABLE 6. Performance metrics of ML-based prediction models used on the training set and on the new data set (internal validation)

\begin{tabular}{lccc}
\hline & \multicolumn{3}{c}{ Endpoint } \\
\cline { 2 - 4 } \multicolumn{1}{c}{ Performance Metric } & GTR & $\begin{array}{c}\text { Early Postop } \\
\text { Remission }\end{array}$ & $\begin{array}{c}\text { Long-Term } \\
\text { Remission }\end{array}$ \\
\hline Algorithm & KNN & SVM & GBM \\
\hline Training (bootstrapping) & & & \\
\hline AUC & 0.993 & 0.681 & 0.719 \\
\hline Accuracy & $96.3 \%$ & $86.1 \%$ & $74.3 \%$ \\
\hline Sensitivity & $97.0 \%$ & $89.1 \%$ & $82.4 \%$ \\
\hline Specificity & $88.9 \%$ & $14.3 \%$ & $35.4 \%$ \\
\hline PPV (precision) & $99.0 \%$ & $96.1 \%$ & $82.4 \%$ \\
\hline NPV & $72.7 \%$ & $5.3 \%$ & $40.5 \%$ \\
\hline F1 score & 0.980 & 0.925 & 0.838 \\
\hline Testing (internal validation) & & & \\
\hline AUC & 0.988 & 1.00 & 0.783 \\
\hline Accuracy & $96.8 \%$ & $100 \%$ & $80.7 \%$ \\
\hline Sensitivity & $96.4 \%$ & $100 \%$ & $95.7 \%$ \\
\hline Specificity & $100 \%$ & $100 \%$ & $37.5 \%$ \\
\hline PPV (precision) & $100 \%$ & $100 \%$ & $81.5 \%$ \\
\hline NPV & $75.0 \%$ & $100 \%$ & $75.0 \%$ \\
\hline F1 score & 0.982 & 1.00 & 0.880 \\
\hline Brier score & 0.035 & 0.097 & 0.151 \\
\hline
\end{tabular}


other hand, for the same reasons, larger patient series and validations of predictive models in routine clinical settings are required to confirm the effectiveness of ML application in pituitary disorders.

\section{Acknowledgments}

We thank Dr. Giorgio Frank for his fundamental clinical and scientific assistance, not limited to the current study but also including all of the activities of our team.

\section{References}

1. Akbari H, Macyszyn L, Da X, Wolf RL, Bilello M, Verma $\mathrm{R}$, et al: Pattern analysis of dynamic susceptibility contrastenhanced MR imaging demonstrates peritumoral tissue heterogeneity. Radiology 273:502-510, 2014

2. Asioli S, Righi A, Iommi M, Baldovini C, Ambrosi F, Guaraldi F, et al: Validation of a clinicopathological score for the prediction of post-surgical evolution of pituitary adenoma: retrospective analysis on 566 patients from a tertiary care centre. Eur J Endocrinol 180:127-134, 2019

3. Azimi P, Benzel EC, Shahzadi S, Azhari S, Mohammadi HR: The prediction of successful surgery outcome in lumbar disc herniation based on artificial neural networks. J Neurosurg Sci 60:173-177, 2016

4. Berker M, Işikay I, Berker D, Bayraktar M, Gürlek A. Early promising results for the endoscopic surgical treatment of Cushing's disease. Neurosurg Rev 37:105-114

5. Bibault JE, Giraud P, Burgun A: Big Data and machine learning in radiation oncology: state of the art and future prospects. Cancer Lett 382:110-117, 2016

6. Biller BM, Grossman AB, Stewart PM, Melmed S, Bertagna $\mathrm{X}$, Bertherat J, et al: Treatment of adrenocorticotropin-dependent Cushing's syndrome: a consensus statement. J Clin Endocrinol Metab 93:2454-2462, 2008

7. Cebula H, Baussart B, Villa C, Assié G, Boulin A, Foubert L, et al: Efficacy of endoscopic endonasal transsphenoidal surgery for Cushing's disease in 230 patients with positive and negative MRI. Acta Neurochir (Wien) 159:1227-1236, 2017

8. Celtikci E: A systematic review on machine learning in neurosurgery: the future of decision-making in patient care. Turk Neurosurg 28:167-173, 2018

9. Chandler WF, Barkan AL, Hollon T, Sakharova A, Sack J, Brahma B, et al: Outcome of transsphenoidal surgery for Cushing disease: a single-center experience over 32 years. Neurosurgery 78:216-223, 2016

10. Ciric I, Zhao JC, Du H, Findling JW, Molitch ME, Weiss RE, et al: Transsphenoidal surgery for Cushing disease: experience with 136 patients. Neurosurgery 70:70-81, 2012

11. Dehdashti AR, Gentili F: Current state of the art in the diagnosis and surgical treatment of Cushing disease: early experience with a purely endoscopic endonasal technique. Neurosurg Focus 23(3):E9, 2007

12. Deo RC: Machine learning in medicine. Circulation 132:1920-1930, 2015

13. Eberlin LS, Norton I, Dill AL, Golby AJ, Ligon KL, Santagata $\mathrm{S}$, et al: Classifying human brain tumors by lipid imaging with mass spectrometry. Cancer Res 72:645-654, 2012

14. El Azami M, Hammers A, Jung J, Costes N, Bouet R, Lartizien C: Detection of lesions underlying intractable epilepsy on T1-weighted MRI as an outlier detection problem. PLoS One 11:e0161498, 2016

15. Emblem KE, Pinho MC, Zöllner FG, Due-Tonnessen P, Hald JK, Schad LR, et al: A generic support vector machine model for preoperative glioma survival associations. Radiology 275:228-234, 2015

16. Esposito F, Dusick JR, Cohan P, Moftakhar P, McArthur D, Wang C, et al: Clinical review: Early morning cortisol levels as a predictor of remission after transsphenoidal surgery for Cushing's disease. J Clin Endocrinol Metab 91:7-13, 2006

17. Focke NK, Yogarajah M, Symms MR, Gruber O, Paulus W, Duncan JS: Automated MR image classification in temporal lobe epilepsy. Neuroimage 59:356-362, 2012

18. Foroni R, Giri MG, Gerosa MA, Nicolato A, Piovan E, Zampieri PG, et al: A euristic approach to the volume reconstruction of arteriovenous malformations from biplane angiography. Stereotact Funct Neurosurg 64 (Suppl 1):134-146, 1995

19. Frank G, Pasquini E, Farneti G, Mazzatenta D, Sciarretta V, Grasso V, et al: The endoscopic versus the traditional approach in pituitary surgery. Neuroendocrinology 83:240248, 2006

20. Frank G, Pasquini E: Endoscopic endonasal cavernous sinus surgery, with special reference to pituitary adenomas. Front Horm Res 34:64-82, 2006

21. Gazit T, Andelman F, Glikmann-Johnston Y, Gonen T, Solski A, Shapira-Lichter I, et al: Probabilistic machine learning for the evaluation of presurgical language dominance. J Neurosurg 125:481-493, 2016

22. Grossman RL, Heath AP, Ferretti V, Varmus HE, Lowy DR, Kibbe WA, et al: Toward a shared vision for cancer genomic data. N Engl J Med 375:1109-1112, 2016

23. Guignat L, Bertherat J: The diagnosis of Cushing's syndrome: an Endocrine Society Clinical Practice Guideline: commentary from a European perspective. Eur J Endocrinol 163:9-13, 2010

24. Hollon TC, Parikh A, Pandian B, Tarpeh J, Orringer DA, Barkan AL, et al: A machine learning approach to predict early outcomes after pituitary adenoma surgery. Neurosurg Focus 45(5):E8, 2018

25. Jacquesson T, Frindel C, Kocevar G, Berhouma M, Jouanneau E, Attyé A, et al: Overcoming challenges of cranial nerve tractography: a targeted review. Neurosurgery 84:313-325, 2019

26. Jagannathan J, Smith R, DeVroom HL, Vortmeyer AO, Stratakis CA, Nieman LK, et al: Outcome of using the histological pseudocapsule as a surgical capsule in Cushing disease. J Neurosurg 111:531-539, 2009

27. Jane JA Jr, Thapar K, Kaptain GJ, Maartens N, Laws ER Jr: Pituitary surgery: transsphenoidal approach. Neurosurgery 51:435-444, 2002

28. Johnson AEW, Ghassemi MM, Nemati S, Niehaus KE, Clifton DA, Clifford GD: Machine learning and decision support in critical care. Proc IEEE Inst Electr Electron Eng 104:444-466, 2016

29. Jones TL, Byrnes TJ, Yang G, Howe FA, Bell BA, Barrick TR: Brain tumor classification using the diffusion tensor image segmentation (D-SEG) technique. Neuro Oncol 17:466476,2015

30. Juan-Albarracín J, Fuster-Garcia E, Manjón JV, Robles M, Aparici F, Martí-Bonmatí L, et al: Automated glioblastoma segmentation based on a multiparametric structured unsupervised classification. PLoS One 10:e0125143, 2015

31. Kalkanis SN, Kast RE, Rosenblum ML, Mikkelsen T, Yurgelevic SM, Nelson KM, et al: Raman spectroscopy to distinguish grey matter, necrosis, and glioblastoma multiforme in frozen tissue sections. J Neurooncol 116:477-485, 2014

32. Kanevsky J, Corban J, Gaster R, Kanevsky A, Lin S, Gilardino M: Big data and machine learning in plastic surgery: a new frontier in surgical innovation. Plast Reconstr Surg 137:890e-897e, 2016

33. Keihaninejad S, Heckemann RA, Gousias IS, Hajnal JV, Duncan JS, Aljabar P, et al: Classification and lateralization of temporal lobe epilepsies with and without hippocampal atrophy based on whole-brain automatic MRI segmentation. PLoS One 7:e33096, 2012 
34. Knosp E, Steiner E, Kitz K, Matula C: Pituitary adenomas with invasion of the cavernous sinus space: a magnetic resonance imaging classification compared with surgical findings. Neurosurgery 33:610-618, 1993

35. Kohli M, Prevedello LM, Filice RW, Geis JR: Implementing machine learning in radiology practice and research. AJR Am J Roentgenol 208:754-760, 2017

36. Kourou K, Exarchos TP, Exarchos KP, Karamouzis MV, Fotiadis DI: Machine learning applications in cancer prognosis and prediction. Comput Struct Biotechnol J 13:8-17, 2014

37. Liu Y, Liu X, Hong X, Liu P, Bao X, Yao Y, et al: Prediction of recurrence after transsphenoidal surgery for Cushing's disease: the use of machine learning algorithms. Neuroendocrinology 108:201-210, 2019

38. Lonser RR, Nieman L, Oldfield EH: Cushing's disease: pathobiology, diagnosis, and management. J Neurosurg 126:404-417, 2017

39. Micko AS, Wöhrer A, Wolfsberger S, Knosp E: Invasion of the cavernous sinus space in pituitary adenomas: endoscopic verification and its correlation with an MRI-based classification. J Neurosurg 122:803-811, 2015

40. Mitchell TM: Machine Learning. New York: McGraw-Hill Science, 1997

41. Netea-Maier RT, van Lindert EJ, den Heijer M, van der Eerden A, Pieters GF, Sweep CG, et al: Transsphenoidal pituitary surgery via the endoscopic technique: results in 35 consecutive patients with Cushing's disease. Eur J Endocrinol 154:675-684, 2006

42. Nieman LK, Biller BM, Findling JW, Murad MH, NewellPrice J, Savage MO, et al: Treatment of Cushing's syndrome: an endocrine society clinical practice guideline. J Clin Endocrinol Metab 100:2807-2831, 2015

43. Nieman LK, Biller BM, Findling JW, Newell-Price J, Savage MO, Stewart PM, et al: The diagnosis of Cushing's syndrome: an Endocrine Society Clinical Practice Guideline. J Clin Endocrinol Metab 93:1526-1540, 2008

44. Obermeyer Z, Emanuel EJ: Predicting the future-big data, machine learning, and clinical medicine. $\mathbf{N}$ Engl J Med 375:1216-1219, 2016

45. Osamura RY, Grossman A, Korbonits M, Kovacs K, Lopes MBS, Matsuno A: Pituitary adenoma, in Lloyd RV, Osamura RY, Kloppel G, et al (eds): World Health Organization Classification of Tumours of Endocrine Organs, 4th ed. Lyon: IARC, 2017, pp 14-18

46. Prevedello DM, Pouratian N, Sherman J, Jane JA Jr, Vance ML, Lopes MB, et al: Management of Cushing's disease: outcome in patients with microadenoma detected on pituitary magnetic resonance imaging. J Neurosurg 109:751-759, 2008

47. Saha M, Mukherjee R, Chakraborty C: Computer-aided diagnosis of breast cancer using cytological images: a systematic review. Tissue Cell 48:461-474, 2016

48. Saha A, Tso S, Rabski J, Sadeghian A, Cusimano MD: Machine learning applications in imaging analysis for patients with pituitary tumors: a review of the current literature and future directions. Pituitary [epub ahead of print], 2020.

49. Schmidt B, Bocklisch SF, Pässler M, Czosnyka M, Schwarze JJ, Klingelhöfer J: Fuzzy pattern classification of hemodynamic data can be used to determine noninvasive intracranial pressure. Acta Neurochir Suppl 95:345-349, 2005

50. Semple PL, Vance ML, Findling J, Laws ER Jr: Transsphenoidal surgery for Cushing's disease: outcome in patients with a normal magnetic resonance imaging scan. Neurosurgery 46:553-559, 2000

51. Senders JT, Staples PC, Karhade AV, Zaki MM, Gormley WB, Broekman MLD, et al: Machine learning and neurosurgical outcome prediction: a systematic review. World Neurosurg 109:476-486.e1, 2018

52. Senders JT, Zaki MM, Karhade AV, Chang B, Gormley
WB, Broekman ML, et al: An introduction and overview of machine learning in neurosurgical care. Acta Neurochir (Wien) 160:29-38, 2018

53. Shimon I, Ram Z, Cohen ZR, Hadani M: Transsphenoidal surgery for Cushing's disease: endocrinological follow-up monitoring of 82 patients. Neurosurgery 51:57-62, 2002

54. Shin SS, Gardner PA, Ng J, Faraji AH, Agarwal N, Chivukula S, et al: Endoscopic endonasal approach for adrenocorticotropic hormone-secreting pituitary adenomas: outcomes and analysis of remission rates and tumor biochemical activity with respect to tumor invasiveness. World Neurosurg 102:651-658.e1, 2017

55. Siccoli A, de Wispelaere MP, Schröder ML, Staartjes VE: Machine learning-based preoperative predictive analytics for lumbar spinal stenosis. Neurosurg Focus 46(5):E5, 2019

56. Skrobala A: Beam orientation in stereotactic radiosurgery using artificial neural network. Radiother Oncol 103 (Suppl 1):S220, 2012 (Abstract)

57. Smith TR, Hulou MM, Huang KT, Nery B, de Moura SM, Cote DJ, et al: Complications after transsphenoidal surgery for patients with Cushing's disease and silent corticotroph adenomas. Neurosurg Focus 38(2):E12, 2015

58. Staartjes VE, de Wispelaere MP, Vandertop WP, Schröder ML: Deep learning-based preoperative predictive analytics for patient-reported outcomes following lumbar discectomy: feasibility of center-specific modeling. Spine J 19:853-861, 2019

59. Staartjes VE, Schröder ML: Class imbalance in machine learning for neurosurgical outcome prediction: are our models valid? J Neurosurg Spine 29:611-612, 2018 (Letter)

60. Staartjes VE, Serra C, Muscas G, Maldaner N, Akeret K, van Niftrik CHB, et al: Utility of deep neural networks in predicting gross-total resection after transsphenoidal surgery for pituitary adenoma: a pilot study. Neurosurg Focus 45(5):E12, 2018

61. Staartjes VE, Zattra CM, Akeret K, Maldaner N, Muscas G, Bas van Niftrik CH, et al: Neural network-based identification of patients at high risk for intraoperative cerebrospinal fluid leaks in endoscopic pituitary surgery. J Neurosurg [epub ahead of print June 21, 2019. DOI: 10.3171/2019.4.JNS19477]

62. Starke RM, Reames DL, Chen CJ, Laws ER, Jane JA Jr: Endoscopic transsphenoidal surgery for cushing disease: techniques, outcomes, and predictors of remission. Neurosurgery 72:240-247, 2013

63. Taghva A: An automated navigation system for deep brain stimulator placement using hidden Markov models. Neurosurgery 66 (3 Suppl Operative):108-117, 2010

64. Taghva A: Hidden semi-Markov models in the computerized decoding of microelectrode recording data for deep brain stimulator placement. World Neurosurg 75:758-763, 2011

65. Vallette-Kasic S, Dufour H, Mugnier M, Trouillas J, ValdesSocin H, Caron P, et al: Markers of tumor invasion are major predictive factors for the long-term outcome of corticotroph microadenomas treated by transsphenoidal adenomectomy. Eur J Endocrinol 143:761-768, 2000

66. Wagenmakers MA, Boogaarts HD, Roerink SH, Timmers HJ, Stikkelbroeck NM, Smit JW, et al: Endoscopic transsphenoidal pituitary surgery: a good and safe primary treatment option for Cushing's disease, even in case of macroadenomas or invasive adenomas. Eur J Endocrinol 169:329-337, 2013

67. Zoli M, Milanese L, Bonfatti R, Sturiale C, Pasquini E, Frank G, et al: Cavernous sinus invasion by pituitary adenomas: role of endoscopic endonasal surgery. J Neurosurg Sci 60:485-494, 2016

\section{Disclosures}

The authors report no conflict of interest concerning the materi- 
als or methods used in this study or the findings specified in this paper.

\section{Author Contributions}

Conception and design: Zoli. Acquisition of data: Zoli, Friso, Rustici. Analysis and interpretation of data: Zoli, Staartjes, Friso, Rustici. Drafting the article: Zoli, Staartjes, Friso, Rustici, Sollini. Critically revising the article: Zoli, Staartjes, Guaraldi, Asioli, Sollini, Serra. Reviewed submitted version of manuscript: Zoli, Guaraldi, Asioli, Pasquini, Regli, Serra, Mazzatenta. Approved the final version of the manuscript on behalf of all authors: Zoli. Study supervision: Staartjes, Pasquini, Regli, Serra, Mazzatenta.

\section{Supplemental Information}

\section{Online-Only Content}

Supplemental material is available online.

Supplementary Content 1. https://thejns.org/doi/suppl/10.3171/ 2020.3.FOCUS2060.

\section{Previous Presentations}

Portions of this paper were presented as oral communications at the 68th Congress of the Italian Society of Neurosurgery, Rome, September 16-18, 2019, and the 19th Congress of the European Association of Neurosurgical Societies, Dublin, September 28, 2019.

\section{Correspondence}

Matteo Zoli: IRCCS Institute of Neurological Sciences of Bologna, University of Bologna, Italy, matteo.zoli4@unibo.it. 